\title{
OS BENEFÍCIOS DO ENSINO MUSICAL NA FORMAÇÃO E DESENVOLVIMENTO HUMANO
}

\section{THE BENEFITS OF MUSICAL TEACHING IN HUMAN TRAINING AND DEVELOPMENT}

\author{
Sonia Regina Albano De Lima \\ Universidade Estadual Paulista \\ soniaalbano@uol.com.br \\ Ana Lucia Nogueira Braz \\ Universidade Anhembi Morumbi \\ aninhabraz@ig.com.br
}

\section{Resumo}

O texto em questão tem como objetivo demonstrar em que medida a música, enquanto área de conhecimento, pode contribuir na formação e no desenvolvimento integral dos indivíduos e quais as zonas do corpo físico e psíquico que podem ser acionadas no contato com a música. A fundamentação teórica está embasada nos textos de Maria Cândida Moraes (2003), A. Storr (2002), S Viellard e E. Bigan (2005), entre outros, na maioria, pesquisadores focados na cognição musical.

Palavras-Chave: ensino musical; desenvolvimento humano; benefícios; cognição musical.

\section{Abstract}

The text in question aims to demonstrate to what extent music, as an area of knowledge, can contribute to the formation and integral development of individuals and which areas of the physical and psychic body can be activated in contact with music. The theoretical foundation is based on texts by Maria Cândida Moraes (2003), A. Storr (2002), S Viellard and E. Bigan (2005), among others, mostly researchers focused on musical cognition.

Keywords: musical education; human development; benefits; musical cognition. 
$\bigcirc$ presente trabalho tem o objetivo de demonstrar o quanto a música, enquanto área de conhecimento, pode contribuir na formação e no desenvolvimento integral dos indivíduos. Os paradigmas que norteiam a educação nos últimos decênios têm se tornado um tanto ineficazes frente a um mundo globalizado. A inserção crescente da tecnologia no aparato escolar e na sociedade, a heterogeneidade sociocultural, a necessidade de integrar socialmente indivíduos com deficiência física e mental de vários níveis, menores carentes e classes desassistidas, não tem se coadunado com uma educação musical tecnicista que, a bem da verdade, trabalha voltada em grande parte para a formação de um profissional mais capacitado para o mercado de trabalho.

Apesar dos ordenamentos voltados para a educação propagarem um ensino democratizado, intercultural, multidisciplinar e pluralista, os processos de ensino e as matrizes curriculares dos cursos de formação parecem estar engessados e bastante morosos frente às mudanças sociais presentes no mundo. Na sala de aula encontramos em cada indivíduo uma mostra da complexidade social que acerca o país e que não tem voz frente a um padrão pedagógico homogeneizado. Esta realidade está bem presente no ensino formal, considerando-se a massificação do ensino imposto pelas políticas públicas de cima para baixo, sem se dar conta das necessidades que acercam o corpo discente, o corpo docente e as próprias instituições no sentido de propagar uma formação mais humanista. Prioriza-se mais celeremente a capacitação profissional e não o desenvolvimento integral dos indivíduos.

Como bem expressa Moraes (2003), a aprendizagem resulta de mudanças estruturais que o organismo segue em congruência com as mudanças do meio. Assim, o comportamento adequado para o ensino envolve uma visão relacional de mudanças estruturais. Um sistema de ensino que não contempla esse ir e vir torna-se pouco útil para agregar novos valores, funções e significados socioculturais, formando pessoas não tão capacitadas para integrar e participar da sociedade de forma benéfica.

Uma educação adequada para o nosso milênio deveria priorizar um conhecimento voltado para a formação integral do indivíduo - para o seu desenvolvimento intelectual, psicológico, sociocultural e ecológico (Moraes, 2003, p 18). Só por meio desta atitude, é que a educação poderia auxiliar o indivíduo a se conciliar mais intensamente com 0

\section{7}

REV. TULHA, RIBEIRÃO PRETO, v. 7, n. 1 pp. 176-190, jan.-jun. 2021 
mundo e transmutar a realidade atual. Novas bases epistemológicas e de ação precisam integrar o ensino formal de música.

Embora as políticas públicas tenham introduzido a necessidade de adotarmos um pensamento interdisciplinar, observamos na educação, o emprego de uma interdisciplinaridade pedagógica que tem se consubstanciado como integração de diferentes disciplinas, mas não toma para si a necessidade de integrar todas as dimensões que circundam a existência humana, sejam elas: psicológica, emotiva, cognitiva, sociocultural, artística, estética, entre outras.

A nossa realidade pedagógica ainda tem trabalhado com uma educação informativa e não com uma educação formativa. O privilégio atribuído às ciências exatas e ao aprendizado da linguagem verbal em detrimento do aprendizado das ciências ditas sociais e o ensino das artes, ainda prevalece. $\bigcirc$ tecnicismo continua a ser o termômetro da educação, pois produz a melhor capacitação do indivíduo para atuar de forma eficiente no mercado de trabalho.

Sob esta ótica, o estudo das artes e particularmente o ensino musical, ainda ocupa um papel insignificante na cadeia formativa. Embora a sociedade tenha na Arte uma parte importante da sua existência, os cursos superiores de ensino artístico e o ensino das artes na educação formal são minoritários, frente às demais formações profissionais. A educação não tem trabalhado a Arte como uma ferramenta importante para o desenvolvimento humano, seja sob a perspectiva de trazer para o indivíduo um valor estético, seja para the possibilitar formas prazerosas e sensiveis de se relacionar com o mundo e consigo mesmo. Ainda não são valorizados na educação, os benefícios, habilidade e capacidades cognitivas e sensoriais que as artes podem trazer para o indivíduo, mesmo se considerando o fato de que esse ensino se tornou obrigatório na educação básica após a implantação da LDB n. 9394/96 e leis complementares.

Se tomarmos como exemplo o ensino musical, vamos observar que ele é capaz de integrar em si, diversas habilidades e capacidades cognitivas. Estudos científicos admitem que a música propicia ao indivíduo, o refinamento de diversas áreas do conhecimento, contribui para o seu desenvolvimento global e melhora suas capacidades relacionais e 
intelectivas. Gardner (1997) vê a música como uma faculdade universal capaz de agregar de forma benéfica os individuos à sociedade. Ela amplia o senso estético, ativa a percepção de forma geral, estimula o sistema simbólico e lógico e as relações subjetivas envolvidas neste processo. Para ele o ensino musical faz parte da trajetória natural de evolução do ser humano, portanto, deve ser estimulado desde o nascimento.

A inter-relação da música com inúmeras áreas do conhecimento está presente em sua estrutura formal, comportando padrões matemáticos e linguísticos há muito estudados desde a Grécia Antiga, o que viabiliza sua inserção na educação como meio de auxiliar a aprendizagem nesses setores. Na Grécia Antiga, desde Homero até bem próximo à Leibniz, a música esteve pautada em princípios pitagóricos, revelando uma estreita ligação com o universo e o número (LIMA, 2005/2007)

No Romantismo, seguindo a tradição cultural da época, a música projeta-se como uma forma de reação da emoção contra a razão; da natureza contra a artificialidade; da simplicidade contra a complexidade e, da fé contra o ceticismo, penetrando sensivelmente na psiquê e no inconsciente humano:

La razón podría hacer ça disección de las partes sin vida pero solo la emoción podría discemir al todo vivo; la razón podría registrar las apariencias exteriores, pero solo la emoción podría penetrar en el corazón y en el espíritu. Para comienzos del siglo XIX se estaba de acuerdo en que la música era, entre las artes, la que mejor podia expresar las profundidades de los sentimientos humanos, no en el lenguaje convencionalizado de los afectos sino en acentos más profundos aunque menos definidos. El tipo de comunicación sufrió un cambio sutil: en lugar de la presentación objetiva del símbolo de la emoción, el compositor romántico buscaba purgarse a través de la producción de su obra, una espécie de catarsis (ROUEL, 2005, p. 118).

Neste período a música passa a ser a arte mais apropriada para expressar um sentimento; a obra musical não necessitava traduzir 
suas emoções em palavras, o próprio texto musical já veiculava uma linguagem de sentimentos.

Contemporaneamente, mesmo consideradas as relações profundas da música com a matemática, a retórica e a linguagem dos sentimentos, ela tem sido estudada por outras áreas de conhecimento, como um produto da atividade humana. Ela se origina no cérebro humano e, como tal, possui características culturais provenientes das diversas sociedades na qual ela se propaga, além de contemplar a própria estrutura emocional e cognitiva dos indivíduos.

psicólogo Storr, seguidor desse pensamento, vê a música como uma grande promotora de ordem. As razões pelas quais ela afeta o homem estão justamente no seu poder de estruturar a experiência auditiva:

Cuando participamos de la música o escuchamos una interpretación que nos embeleza, nos aislamos, de forma temporal, de otros estímulos externos. Entramos en un mundo especial y apartado donde prevalece el ordem y las incongruencias no tienen cabída [...] se trata de un "retir" temporal que facilita un processo de recordenación mental, lo cual propicia la adaptación al mundo exterior y no constituye una via de escape (STORR, 2002, p. 139)

Este autor vê o homem sempre preocupado em ordenar o caos, portanto, a formação de novos padrões musicais para o ser humano é uma atividade mental contínua que se dá até inconscientemente. Ele cita como exemplo o fato de estarmos continuadamente encaixando durante o sono, de forma intermitente, peças, objetos ou pensamentos. Assim, vislumbramos no cérebro um processo de classificação e exploração pela qual a experiência presente relaciona-se com a passada. Realmente, não é tão incomum lembrarmo-nos de sonhos, nos quais dirigimos nossa atenção para a ordenação de coisas antes desordenadas: 
Sin embargo, cuando distinguimos una conexión inesperada, un nuevo patrón, experimentamos una profunda satisfacción. [...] cuando se descubre un nuevo esquema, este suele tener mucha importancia para el descubridor, así como para todos los que lo comprenden y aprecian. Esto es válido no solo para teorias científicas y otros intentos intelectuales por encontrar un sentido al universo, sino también para las obras de arte que son algo más que una mera repetición de sus precursoras. Y exclamamos "Eureka!" ante el placer de descubrir una nueva Gestalt, aunque ésta no tenga una aplicación cotidiana inmediata. (IBID, p. 221)

Ainda segundo Storr, a obtenção de padrões coerentes de pensamento a partir de ideias abstratas é uma conquista humana importante. No caso da música, essa conquista cativa e satisfaz os indivíduos capazes de entendê-la. Trata-se de um tipo de apreciação estética que traz comoção, pois não se configura como um simples exercício cerebral, uma vez que o homem sente prazer percebendo a coerência e harmonia onde antes não havia.

A música detém outros predicados importantes, ela traz para si a tradição cultural, a diversidade e influencia diretamente as nossas emoções, portanto, ela atua mais inteiramente em nosso corpo: "Sin embargo, debido a sus efectos físicos, la música estimula un orden interno que las matemáticas no son capazes de gerar" (ibid, 229). Ela é menos abstrata que a matemática, porque promove estimulações fisiológicas, sensoriais e porque os sons que ela produz são formas de comunicação emocional. Ela agrega a emoção e o intelecto e restabelece a conexão entre a mente e o corpo. Por essa razão, Storr considera-a mais importante que a matemática, por ter maior contato com a nossa vida subjetiva:

La gran música siempre expresa algo que transciende lo personal porque depende de um proceso de ordenación interna que es, en gran parte, inconsciente y que, por tanto, no ha sido dispuesto de forma liberada por el compositor. Este proceso de ordenación deve alentarse y anhelarse, debemos esperarlo y rezar para que se produzca. Los grandes logros creativos del ser humano son producto de su cerebro, pero ello no implica que sean elaboracionaes 
del todo conscientes. El cerebro opera de formas misteriosas que escapan al control de la voluntad: a veces debemos dejarlo funcionar "a sua aire" para que sea más efectivo (STORR, 2002, p. 233)

Estudos mais recentes têm demonstrado que mesmo os sentimentos estéticos da música, estão relacionados com o processamento neural da informação. Tal fato corrobora ainda mais as afirmativas de A. Storr. livro de Roederer (1998), ao se reportar ao aspecto estético da música assim se manifesta:

Mesmo os sentimentos estéticos estão relacionados com - processamento neural de informação. A mistura, tão característica de padrões regulares e ordenados alternados com surpresa e incerteza, comum a toda entrada sensorial classificada como "estética", pode ser essencialmente uma manifestação inata do homem de exercitar a sua rede neural super-redundante com operações de processamento de informações não-essenciais de complexidade variável ou alternante. Sabemos nós, realmente, o que é música?..... Em quase todas as culturas, a música consiste em sucessões e superposições organizadas e ritmicamente estruturadas de sons relacionados a partir de um repertório muito limitado das alturas discretas de uma determinada escala. [...] A música pode ser um subproduto bastante natural da evolução da fala e da linguagem. Nessa evolução, que indubitavelmente foi um fator essencial para o desenvolvimento da raça humana, surgiu uma rede neural capaz de executar as ultracomplexas operações de processamento, identificação, armazenagem e recuperação de som que são necessárias para o reconhecimento fonético, a identificação da voz e a compreensão da fala (ROEDERER, 1998, p. 33).

Sandrine Vieillard, pesquisadora do Laboratório de Neuropsicologia da Música e da Cognição Auditiva e Emmanuel Bigand, professor de psicologia cognitiva, dirigente do Laboratório de Estudos da Aprendizagem e do Desenvolvimento, da Universidade de Bourgogne, em Dijon, nos artigos publicados na Revista Científica Viver Mente \& Cérebro (2005), admitem que a música produz, de fato, reações fisiológicas cuja amplitude parece depender do significado emocional. $\bigcirc$ fato de essas reações fisiológicas serem independentes dos julgamentos objetivos e subjetivos demonstra que a música exerce

\section{2}


grande poder sobre o comportamento humano e que o ouvinte não está necessariamente consciente do efeito que ela exerce sobre ele.

Outros estudos demonstraram que a música ativa as mesmas zonas cerebrais que participam do processamento de emoções (sistema límbico). Deduz-se, e este é um ponto importante, que a música não evoca emoções apenas de acordo com a história pessoal de cada um, mas, de fato, ela as provoca.

As emoções provenientes da música resultariam de processos cognitivos específicos. Elas dependem da compreensão dos elementos da estrutura musical de uma obra. Com o auxilio de técnicas de imageamento cerebral, ou seja, por meio do exame PET Scan (Positron Emission Tomography ou, Tomografia por Emissão de Pósitrons) várias equipes estudaram as consequências de uma longa formação musical, comparando as características anatômicas e funcionais do cérebro de músicos e de não músicos. Descobriram que aprender a tocar um instrumento reorganiza diversas regiões cerebrais (áreas motoras, corpo caloso e cerebelo), incluindo aquelas diretamente envolvidas na percepção musical. Além disso, o cérebro do músico também sofre ativações mais fortes no hemisfério esquerdo (o da linguagem e cognição). Essas diferenças são mais significativas em pessoas que começaram a estudar música na infância, já que ela produz maior plasticidade cerebral. Os exercícios musicais, também beneficiam a memória e a resolução de tarefas espaciais.

Segundo Agudelo e Soto (2002), há estudos científicos que vem comprovando que a música tem a capacidade de influenciar o ser humano nos aspectos, biológico, emocional, intelectual, social e psicológico. Resultados de estudos realizados no Instituto de Neurologia de Londres indicam que o corpo caloso (estrutura que une e leva informação do hemisfério cerebral direito e esquerdo) é mais desenvolvido nos músicos, o que pode comprovar que a música desenvolve e aumenta conexões neurais, estimulando a inteligência (hemisfério esquerdo do cérebro), a sensibilidade e criatividade (hemisfério direito do cérebro)

- ser humano, ao entrar em contato com a música, aciona zonas importantes do corpo físico e psíquico (os sentidos, as emoções e a cognição). As representações mentais e sensoriais projetadas pela música são isentas de juízo de valor, situação que possibilita a liberação de cargas emocionais há muito represadas no organismo. Miranda e Codeli (2003) afirmam que a música interfere em estados afetivoemocionais de quem os escuta, fazendo surgir emoções e sentimentos, 
por meio de associações extramusicais agradáveis ou desagradáveis.

Clair e Memmott (2008), no livro Therapeutic Uses of Music with Older Adult, afirmam que com a música é possivel:

* Influenciar respostas fisiológicas, por meio de qualidades sedativas ou estimulantes que as musicas tem e que afetam respostas como pressão arterial, frequência cardíaca, respiração, tolerância a dor, etc;

* Estimular respostas emocionais que estão associadas às respostas fisiológicas, como alterações nos estados de animo, nos afetos;

* Promover a integração social, ao criar oportunidades para experiências comuns, que são a base para os relacionamentos;

- Auxiliar na comunicação, principalmente em pessoas que tem problemas de comunicação verbal e que, pela música, conseguem interagir significativamente com os outros;

* Promover a expressão emocional, pois utiliza a comunicação não verbal, facilitando a manifestação das emoções;

* Afastar o indivíduo do desconforto e da rotina cotidiana, mediante o uso do tempo com atividades envolvendo música, melhorando a qualidade de vida;

* Aumentar a capacidade de fazer associações extramusicais ou com outras informações sensoriais que estão guardadas na memória.

Comprova-se ainda, que a percepção advinda de padrões musicais não se reduz apenas a identificar determinados fatores restritos ao ambiente da música, tais como: perceber timbres instrumentais diversos; apreciar pequenas variações de altura de um som; descobrir o desenvolvimento temático de uma sonata, ou perceber ligações entre um tema e variações, entre outros dados musicais. Essa percepção também é capaz de acionar processamentos cognitivos de uma complexidade diferente, pois requer operações cognitivas abstratas que colocam em atividade, capacidades de atenção e memória, operações de categorização e raciocínio. Portanto, é bastante provável que uma prática instrumental intensa leve a reorganizações neurológicas que diferenciem "cérebros músicos" e "cérebros não músicos" no plano

\section{4}

REV. TULHA, RIBEIRÃO PRETO, v. 7, n. I pp. 176-190, jan.-jun. 2021 
motor, sem que isso altere os processos de percepção, compreensão e apreciação dos dois grupos.

Se música é um produto da atividade (mente) humana, sua função também é social. Essa realidade leva-nos a refletir que uma prática musical sensibilizadora e contínua é capaz de produzir na comunidade, a inter-relação de saberes e o amadurecimento racional, estético e afetivo do indivíduo.

A música, pensada como uma das manifestações culturais do homem é palco de pesquisas que estudam alguns aspectos musicais interligados à antropologia, à sociologia, à filosofia, história e ética. Como exemplo temos os voltados para o ecossistema que tem se preocupado em estudar os níveis de aceitação sonora compativeis ao indivíduo.

São inúmeras as interrelações que a música estabelece com as demais áreas do conhecimento, seja no campo das artes, das ciências, da linguagem, da saúde e da educação. Movimentos estéticos importantes, como o impressionismo musical, estão pautados na interconexão entre cor e som. A música e as artes plásticas têm trabalhado em sinergia, de forma que o som é utilizado num contexto de criação plástica, com as esculturas. A atual arte sonora (sound art) tem como peculiaridade a junção de som, artes plásticas, tecnologia, arquitetura como elementos materiais de criação. Ela busca, no espaço, o seu eixo fundamental para a concepção de obra (Campesato \&l lazzetta, 2006). A ópera também se consagra como um gênero musical que integra diversas linguagens: a música, o teatro, a dança, a literatura e a cultura.

A música também pode conduzir o individuo a outros tempos e lugares; colocar em movimento a energia corporal e psíquica; transgredir padrões pré-estabelecidos; desenvolver relações intra e interpessoais; propiciar transformações psicoemocionais, cognitivas, etc. As ligações entre música, ritmo, movimento, alterações corporais, psicológicas, expressam o seu profundo entrelaçamento com o corpo, o psiquismo e os aspectos fisiológicos do indivíduo. Para Campbell (200 l) a música é capaz de gerir a criação de imagens sensoriais que incitam a consciência e mobilizam algumas atividades humanas. Desta maneira, ela é capaz de afetar sensivelmente o comportamento humano.

Fregtman (1995) legitima tal declaração, ao afirmar que atos vitais do ser humano, como a respiração e os batimentos cardíacos, são 
alterados em seus ritmos naturais, quando situações físicas e ambientais externas acontecem, portanto, se empregarmos a música como um elemento externo propiciador, ela pode modificar os estados internos e comportamentais dos indivíduos. Dotada de ritmo, a música possibilita alterações consideráveis do ritmo interno dos organismos, portanto, podemos afirmar, com segurança, que a música é capaz de modificar o funcionamento corporal do homem.

Uma das ligações da música com o movimento se estabelece na dança. $\bigcirc$ homem primitivo já dançava $e$, nesse fazer utilizava 0 canto, a música e os instrumentos musicais por eles produzidos. Música e dança são artes que se complementam, pois, antes de serem encaradas como representação artística, foram formas humanas de manifestação espontânea da vida social. Alguns compositores musicais de dicaram boa parte de sua produção musical na confecção de ballets e produções artísticas que trabalhavam o movimento corporal. Muitas metodologias de ensino musical foram criadas tendo, no movimento corporal e no canto, os alicerces para uma aprendizagem musical efetiva. Técnicas corporais como o Método Laban, a Eutonia, a técnica de Alexander, frequentemente tem sido utilizada pelos músicos com o intuito de combater o estresse corporal e adquirir uma postura saudável em suas performances, o que comprova a extrema ligação entre essas duas áreas.

São comuns na psicologia e na medicina, os estudos que analisam os movimentos do cérebro ao receber um estímulo musical, a relação da música com a afetividade, com a subjetividade e a sensibilidade. A musicoterapia também vem tentando demonstrar o quanto as práticas musicais são capazes de retardar os processos de envelhecimento e as doenças degenerativas.

A música contém bases de ação subjetivas que auxiliam os indivíduos a se reencontrarem com a sua essência psíquica, suas emoções, sem que para isso tenham que recorrer à linguagem verbal. As representações provindas da música não precisam ser explicadas, avaliadas, julgadas, elas simplesmente existem e produzem no indivíduo a "catarse" necessária à liberação das emoções. 
Verifica-se que o aprendizado musical permite ao indivíduo o despertar de diversas habilidades cognitivas: a físico-sinestésica, a espacial, a lógico-matemática, a motora, sem contar com o desenvolvimento das próprias habilidades musicais. $\bigcirc$ trabalho musical intensifica o senso rítmico, o senso espacial, a escuta externa e interna dos indivíduos. As artes quando bem direcionadas podem levar o indivíduo a desvelar o seu próprio interior e se reconhecer como tal (CARDNER, 1994).

Se tantas são as interrelações da música com as outras áreas de conhecimento e se o convívio com ela pode propiciar benefícios que contribuem para o desenvolvimento integral do indivíduo, porque não a utilizar como modelo de ação benéfica nos processos de ensino/ aprendizagem? Talvez tenha sido essa percepção, a causa motivadora da criação da Lei Ordinária n. 1 1.769/08 que obrigou o ensino musical na educação básica brasileira e que hoje foi revogada, dando ensejo a promulgação da Base Nacional Comum Curricular, que apresenta os mesmos objetivos.

Várias são as educadoras musicais e as metodologias de ensino musical que tem evocado a importância de se ministrar aos jovens e as crianças, um ensino musical sensibilizador, com vistas a desenvolver as faculdades de percepção, comunicação, concentração, trabalho em equipe, autoconfiança, reinserção social, criatividade, memória e atenção (CAINZA, 2000; BRITO, 2001 ).

Nessa forma de lidar com a música, a escuta musical diferencia-se de um simples ouvir que apenas recebe os estímulos sonoros presentes no cotidiano, sem valorizar o seu significado. Esta escuta traz embutida uma proposta educativa que amplia a percepção para aspectos cognitivo-musicais antes não observados. A vivência sonora assume neste processo, uma proporção diferenciada, uma vez que, como bem expressa Dilthey (2002) ela é anterior ao pensamento, à comunicação, portanto, expressa mais intensamente a realidade. Ela vem antes mesmo da representação, pois tem inicio ainda no útero materno e são estes sons que vão participar ativamente na formação desse ser humano. 


\section{Sobre as autoras}

Sônia Albano: Doutora em Comunicação e Semiótica - Artes (PUC/SP); pós-doutora em interdisciplinaridade e educação pelo CEPI-PUC/SP; pós-doutora em música pelo IA-UNESP; pós-graduação lato sensu em práticas instrumentais e música de câmara pela FMCG; especialização em interpretação musical e música de câmara com o Prof. Walter Bianchi (FMCG); bacharelado em instrumento - piano (FMCG); bacharelado em direito (USP); licenciatura curta em educação musical e habilitação para o ensino de piano (Instituto Musical de São Paulo). Desde 2005 atua no Programa de Mestrado e Doutorado em Música do IA-UNESP. Possui livros, coletâneas, artigos e pesquisas envolvendo a interdisciplinaridade, música, performance e educação musical. Foi Presidente da Associação Nacional de Pesquisa e Pós-Graduação em Música, de 2015 até 2019.

Ana Lucia Nogueira Braz: Doutora em Psicologia pela Pontifícia Universidade Católica de Campinas (2003), Mestrado em Educação pela Universidade Paulista (1995), graduação em Psicologia pela Universidade Paulista (1983), graduação em Pedagogia pela Faculdade Filosofia Ciências e Letras Carlos Pasqualli (1988). Foi professora da Universidade Paulista de 1984 até 2007; coordenadora dos Cursos de Psicologia da UNIP de 2000 a 2007; professora da Universidade Anhembi- Morumbi e responsável pelo Núcleo de Apoio Psicopedagógico- NAP- da instituição de 2018 a 2020. Foi pesquisadora da FUNADESP. É profissional liberal com consultório particular. É autora do livro $\bigcirc$ significado e a importância do amor- Um estudo fenomenológico; organizadora do livro Arte, cultura e Educação na formação de Docentes: llusão ou Realidade. Autora de capítulos nos livros; Mosaicos: Arte Cultura e Educação; Corpo, Alteridade e Sintoma: Compreensão e Diversidade; Reflexões Atuais sobre temas da Psicologia, além de artigos em revistas científicas. Cursou especialização em Gerontologia Social em 2017 e Intervenções em situações limites em 2016, pelo Instituto Sedes Sapiens. Tem especialização em Fenomenologia pela Universidade de São Paulo-USP. Tem experiência na área de Psicologia Clínica, atuando em consultório particular desde 1984, realizando atendimentos e supervisões. Desenvolve trabalhos nas áreas de desenvolvimento social e da personalidade, atuando principalmente nos seguintes temas: amor, educação emocional; participação do amor na evolução, processo de aprendizagem, desenvolvimento amoroso e relacionamento interpessoal. 


\section{Referências}

ACUDELO, Graciela; SOTO, Gabriela. Incidencias de La música em lós procesos cerebrales. Consejo de La música em México. Forum panamericano y Coloquio sobre Educacion Musical. Mexico 2002. Disponivel em: www.iieh.com/doc/doc200209/50300.html, acessado em 30 abril 2012.

BICAND, Emmanuel. Ouvido Afinado. Viver mente \& cérebro. Revista de Psicologia, psicanaláse, neurociências e conhecimento, ano XIII, n. 149, junho de 2005, p. 59-63.

BRITO, Teca Alencar de. Koellreutter educador - o humano como objetivo da educação musical. São Paulo: Peirópolis, 2001.

CAMPBELL, Don. O efeito Mozart. Rio de Janeiro: Rocco, 2001.

CAMPESATO, Lilian E IAZZETTA, Fernando. Som, Espaço e Tempo na arte sonora. XVI Congresso da ANPPOM. Brasilia, 2006, p. 775-777. Disponível em: www.anppom.com.br/anais/anais congresso_ anppom 2006/CDROM/com/c-248.pdf Acesso em 24 de abril de 2009.

CLAIR Alicia Ann e MEMMOTT Jenny. Therapeutic Uses of Music with Older Adult. American Music Therapy Association, $2^{\circ}$ Ed. 2008.

DILTHEY, Wilhelm. Psicologia e Compreensão: Ideias sobre uma Psicologia Descritiva e Analítica. Lisboa. Edições 70, 2002.

FREGTMAN, Carlos. Corpo, música e terapia, 1Oed. São Paulo, Cultrix, 1995.

GAINZA, Violeta Hemsy de. Estudos de psicopedagogia musical. São Paulo: Summus, 1988.

CARDNER, Howard. As artes e o desenvolvimento humano. Porto Alegre: Artes Médicas Sul, 1997. 
CARDNER, Howard. Educación artística y desarrollo humano. Barcelona: Paidós Educador, 1994.

LIMA, Sonia Albano. A relação da música com a linguagem verbal. In: Uma metodologia de interpretação musical. São Paulo: Musa Editora, 2005, p. $51-80$.

LIMA, Sonia Albano. Música e Cosmologia. IN: LIMA, Sonia Albano (org) Uma Leitura transdisciplinar do fenômeno sonoro. São Paulo: Editora Som\& FMCC. 2007, p. 9-36.

MIRANDA, Maria Luiza de Jesus \& CODELI Maria Regina C. Souza: Música atividade física e bem-estar psicológico em idosos. Revista Brasileira de Ciência e Movimento, v1 I. N4, pag 87 - 94. 2003.

MORAES, Maria Cândida. Educar na biologia do amor e da solidariedade. Petrópolis, RJ: Vozes, 2003.

ROEDERER, Juan C. Música, Física, Psicofísica e Neuropsicologia: uma abordagem interdisciplinar. In: Introdução à física e psicofísica da música. -São Paulo: Editora da Universidade de São Paulo, p. 17-34. 1998. Tradução portuguesa de Alberto Luis da Cunha.

ROWELL, Lewis. Introduccion a la filosofia de la musica: Antecedentes históricos y problemas estéticos. Barcelona: Gedisa. 2005. Tradução para o espanhol de Miguel Wald.

STORR, Anthony. La música y la mente. Barcelona: Editora Paidós, 250 p. Tradução espanhola de Verônica Canales Medina. 2002.

VIEILLARD, Sandrine. Emoções Musicais. Viver mente \& cérebro. Revista de Psicologia, psicanalase, neurociencias e conhecimento, ano XIII, n. 149, junho de 2005, p. 52 a 57. São Paulo: Dinap. S/A. 